\title{
Sequential Statistical Optimization of Media Components for the Production of Glucoamylase by Thermophilic Fungus Humicola grisea MTCC 352
}

\author{
Vinayagam Ramesh and Vytla Ramachandra Murty \\ Department of Biotechnology, Manipal Institute of Technology, Manipal University, Manipal, Karnataka 576104, India \\ Correspondence should be addressed to Vinayagam Ramesh; rameshvinayagam@gmail.com
}

Received 7 May 2014; Revised 25 June 2014; Accepted 28 June 2014; Published 9 July 2014

Academic Editor: Sunney I. Chan

Copyright (c) 2014 V. Ramesh and V. Ramachandra Murty. This is an open access article distributed under the Creative Commons Attribution License, which permits unrestricted use, distribution, and reproduction in any medium, provided the original work is properly cited.

\begin{abstract}
Glucoamylase is an industrially important enzyme which converts soluble starch into glucose. The media components for the production of glucoamylase from thermophilic fungus Humicola grisea MTCC 352 have been optimized. Eight media components, namely, soluble starch, yeast extract, $\mathrm{KH}_{2} \mathrm{PO}_{4}, \mathrm{~K}_{2} \mathrm{HPO}_{4}, \mathrm{NaCl}, \mathrm{CaCl}_{2}, \mathrm{MgSO}_{4} \cdot 7 \mathrm{H}_{2} \mathrm{O}$, and Vogel's trace elements solution, were first screened for their effect on the production of glucoamylase and only four components (soluble starch, yeast extract, $\mathrm{K}_{2} \mathrm{HPO}_{4}$, and $\mathrm{MgSO}_{4} \cdot 7 \mathrm{H}_{2} \mathrm{O}$ ) were identified as statistically significant using Plackett-Burman design. It was fitted into a first-order model $\left(R^{2}=0.9859\right)$. Steepest ascent method was performed to identify the location of optimum. Central composite design was employed to determine the optimum values (soluble starch: $28.41 \mathrm{~g} / \mathrm{L}$, yeast extract: $9.61 \mathrm{~g} / \mathrm{L}, \mathrm{K}_{2} \mathrm{HPO}_{4}: 2.42 \mathrm{~g} / \mathrm{L}$, and $\mathrm{MgSO}_{4} \cdot 7 \mathrm{H}_{2} \mathrm{O}: 1.91 \mathrm{~g} / \mathrm{L}$ ). The experimental activity of $12.27 \mathrm{U} / \mathrm{mL}$ obtained was close to the predicted activity of 12.15 . High $R^{2}$ value (0.9397), low PRESS value (9.47), and AARD values (2.07\%) indicate the accuracy of the proposed model. The glucoamylase production was found to increase from $4.57 \mathrm{U} / \mathrm{mL}$ to $12.27 \mathrm{U} / \mathrm{mL}$, a 2.68 -fold enhancement, as compared to the unoptimized medium.
\end{abstract}

\section{Introduction}

Glucoamylase or 1,4- $\alpha$-D-glucan glucohydrolase (EC 3.2.1.3) is an industrial enzyme which can degrade amylose and amylopectin by hydrolysis of both $\alpha-1,4$ and $\alpha$-1,6 glucosidic links, present in starch, resulting in production of $\beta$ $\mathrm{D}$ glucose [1]. There are two stages in the production of industrial starch syrup: liquefaction and saccharification. In the first step, thermostable $\alpha$-amylases are used to liquefy starch. Following this, saccharification is carried out at 55$60^{\circ} \mathrm{C}$ with fungal glucoamylases. The glucoamylase from mesophilic fungi (e.g., Aspergillus niger) is unstable due to its exposure to higher temperatures for a prolonged duration [2]. This disadvantage necessitates the use of thermostable glucoamylases derived from thermophilic fungal sources [3] for industrial usage.

There are a number of thermophilic fungi such as Thermomyces lanuginosus, Talaromyces duponti, Thermomucor indicae-seudaticae, and Humicola grisea which are capable of producing glucoamylase [4-6]. Literature reveals that Humicola grisea is an attractive source for extracellular thermostable glucoamylase production $[4,7]$. Humicola grisea possesses efficient hydrolytic system which is responsible for the production of many polysaccharide degrading enzymes such as cellulases, amylases, trehalase, beta-glucosidase, and xylanase [8].

Glucoamylase production depends on many media components such as carbon source, nitrogen source, mineral salts, and micronutrients. Therefore it is necessary to optimize the medium components for the enhanced production of glucoamylase [5, 9-11]. The classical one-variable-at-a-time (OVAT) approach involves altering the concentration of one of the components and maintaining the others, at a specified level. This is usually problematic since it is laborious and the interaction effects between the various media components are not taken into consideration. The shortcomings of this approach are overcome by the use of statistical techniques like 
TABLE 1: Different levels of experimental variables used for the production of glucoamylase using Plackett-Burman design.

\begin{tabular}{|c|c|c|c|c|c|}
\hline \multirow{2}{*}{ Symbol } & \multirow{2}{*}{ Variable } & \multirow{2}{*}{ Units } & \multicolumn{3}{|c|}{ Coded level } \\
\hline & & & -1 & 0 & 1 \\
\hline$A$ & Soluble starch & $(\mathrm{g} / \mathrm{L})$ & 5 & 10 & 15 \\
\hline$B$ & Yeast extract & $(\mathrm{g} / \mathrm{L})$ & 1 & 3 & 5 \\
\hline C & $\mathrm{KH}_{2} \mathrm{PO}_{4}$ & $(\mathrm{~g} / \mathrm{L})$ & 0.5 & 1 & 1.5 \\
\hline$D$ & $\mathrm{~K}_{2} \mathrm{HPO}_{4}$ & $(\mathrm{~g} / \mathrm{L})$ & 0.5 & 1 & 1.5 \\
\hline$E$ & $\mathrm{NaCl}$ & $(\mathrm{g} / \mathrm{L})$ & 0.5 & 1 & 1.5 \\
\hline$F$ & $\mathrm{CaCl}_{2}$ & $(\mathrm{~g} / \mathrm{L})$ & 0.5 & 1 & 1.5 \\
\hline$G$ & $\mathrm{MgSO}_{4} \cdot 7 \mathrm{H}_{2} \mathrm{O}$ & $(\mathrm{g} / \mathrm{L})$ & 0.5 & 1 & 1.5 \\
\hline$H$ & Vogel's solution & $(\mathrm{mL})$ & 0.1 & 0.5 & 1 \\
\hline
\end{tabular}

Plackett-Burman design (PBD), steepest ascent, and response surface methodology (RSM) [12].

Beginning from a large collection of factors, PBD helps to identify the main factors that would be taken up for further optimization processes, through lesser number of trials. The significant factors chosen from PBD are sequentially moved along the path of steepest ascent to target the maximum production of glucoamylase. The levels of the components obtained along the region of maximum response are used in central composite design (CCD), a response surface methodology technique. These form the right set of techniques leading to the optimal concentration of the various significant media components. This approach of arriving at the optimal media composition has been practiced by various researchers in many fermentation processes [13-15].

To the best of our knowledge, there are no available reports on the optimization of media components for glucoamylase production using Humicola grisea. Therefore, in the present report, the media components (soluble starch, yeast extract, $\mathrm{KH}_{2} \mathrm{PO}_{4}, \mathrm{~K}_{2} \mathrm{HPO}_{4}, \mathrm{NaCl}, \mathrm{CaCl}_{2}$, $\mathrm{MgSO}_{4} \cdot 7 \mathrm{H}_{2} \mathrm{O}$, and Vogel's trace elements solution) for the production of glucoamylase by Humicola grisea MTCC 352 were optimized using response surface methodology that included a Plackett-Burman design, path of steepest ascent, and central composite design.

\section{Materials and Methods}

2.1. Microorganism, Inoculum Preparation, and Fermentation Conditions. The microorganism, used in the study, Humicola grisea MTCC 352, was obtained from Microbial Type Culture Collection, Chandigarh, India. The strain was maintained on potato dextrose agar (PDA) slant, grown at $45^{\circ} \mathrm{C}$ for 10 days before being stored at $4^{\circ} \mathrm{C}$. The strain was subcultured, once every 2 months.

The fermentation was started with $2 \mathrm{~mL}$ of conidial inoculum prepared using $0.15 \%$ Triton X-100, that was added to $250 \mathrm{~mL}$ Erlenmeyer flasks containing $100 \mathrm{~mL}$ of medium (glucose $1 \mathrm{~g}$, yeast extract $0.3 \mathrm{~g}, \mathrm{KH}_{2} \mathrm{PO}_{4} 0.1 \mathrm{~g}$, $\mathrm{K}_{2} \mathrm{HPO}_{4} 0.1 \mathrm{~g}, \mathrm{NaCl} 0.1 \mathrm{~g}, \mathrm{CaCl}_{2} 0.1 \mathrm{~g}, \mathrm{MgSO}_{4} \cdot 7 \mathrm{H}_{2} \mathrm{O} 0.1 \mathrm{~g}$, and $0.5 \mathrm{~mL}$ of Vogel's trace element solution), adjusted to $\mathrm{pH}$ 6. The inoculum culture was incubated at $45^{\circ} \mathrm{C}$ for 4 days at $150 \mathrm{rpm}$. Vogel's trace elements solution was constituted by the following, as per literature [16]: citric acid monohydrate $5 \mathrm{~g}, \mathrm{ZnSO}_{4} \cdot 7 \mathrm{H}_{2} \mathrm{O} 5 \mathrm{~g}, \mathrm{Fe}\left(\mathrm{NH}_{4}\right)_{2}\left(\mathrm{SO}_{4}\right)_{2} \cdot 6 \mathrm{H}_{2} \mathrm{O} 1 \mathrm{~g}$, $\mathrm{CuSO}_{4} \cdot 5 \mathrm{H}_{2} \mathrm{O} 0.25 \mathrm{~g}, \mathrm{MnSO}_{4} \cdot \mathrm{H}_{2} \mathrm{O} 0.05 \mathrm{~g}, \mathrm{H}_{3} \mathrm{BO}_{3} 0.05 \mathrm{~g}$, and $\mathrm{Na}_{2} \mathrm{MoO}_{4} \cdot 2 \mathrm{H}_{2} \mathrm{O} 0.05 \mathrm{~g}$, dissolved in $95 \mathrm{~mL}$ distilled water.

Based on preliminary experiments (data not shown), soluble starch and yeast extract showed better yields for enzyme production. Therefore, for the production medium, soluble starch was used as the carbon source in place of glucose. All the other media constituents and the culture conditions remained unaltered. Both the inoculum culture and production media were autoclaved for 15 minute at $121^{\circ} \mathrm{C}$ and $15 \mathrm{psi}$. The spore suspension of the fungal strain $(5 \mathrm{~mL})$ was inoculated in $100 \mathrm{~mL}$ of the production medium, taken in a $250 \mathrm{~mL}$ flask, for a period of 4 days.

2.2. Extraction of Extracellular Glucoamylase. After fermentation, the broth was subjected to filtration through Whatman No. 1 filter paper. The filtrate was centrifuged at $13000 \mathrm{rpm}$ for 20 minutes to remove the fungal mycelia. The cell-free supernatant was assayed for glucoamylase activity. All the experiments were carried out in triplicate and the average values were reported.

2.3. Glucoamylase Activity Assay. $0.05 \mathrm{~mL}$ of cell-free supernatant was incubated with $0.7 \mathrm{~mL}$ of $50 \mathrm{mM}$ citrate buffer ( $\mathrm{pH} 5.5$ ) and $0.25 \mathrm{~mL}$ starch solution $\left(1 \%, \mathrm{w} / \mathrm{v}\right.$ ) at $60^{\circ} \mathrm{C}$ for 10 minutes. The reaction was stopped by placing the tubes in a boiling water bath for 10 minutes. After bringing back to room temperature, the concentration of glucose formed was determined by glucose oxidase/peroxidase (GOD/POD) method [17]. One unit of glucoamylase activity was defined as the amount of enzyme that releases $1 \mu \mathrm{mol}$ glucose from soluble starch per minute under assay conditions.

2.4. Plackett-Burman Design. Plackett-Burman design was used to screen the media components and identify the significant components that influence the higher production of glucoamylase. Eight independent variables were chosen with three different levels, namely, low, mid, and high factor settings, coded as $-1,0$, and +1 , respectively, with their actual values (Table 1 ). These variables were screened in 13 experimental runs that included a center point, according to 
TABLE 2: Plackett-Burman experimental design matrix for glucoamylase production.

\begin{tabular}{lccccccccc}
\hline Run & $A$ & $B$ & $C$ & $D$ & $E$ & $F$ & $G$ & $H$ & Glucoamylase activity (U/mL) \\
\hline 1 & 1 & 1 & -1 & 1 & -1 & -1 & -1 & 1 & 6.31 \\
2 & -1 & 1 & 1 & 1 & -1 & 1 & 1 & -1 & 4.87 \\
3 & -1 & 1 & 1 & -1 & 1 & -1 & -1 & -1 & 3.78 \\
4 & -1 & -1 & -1 & -1 & -1 & -1 & -1 & -1 & 3.02 \\
5 & -1 & -1 & -1 & 1 & 1 & 1 & -1 & 1 & 3.97 \\
6 & 1 & -1 & 1 & 1 & -1 & 1 & -1 & -1 & 4.94 \\
7 & -1 & 1 & -1 & -1 & -1 & 1 & 1 & 1 & 4.83 \\
8 & 0 & 0 & 0 & 0 & 0 & 0 & 0 & 0 & 5.57 \\
9 & 1 & 1 & 1 & -1 & 1 & 1 & -1 & 1 & 4.74 \\
10 & -1 & -1 & 1 & 1 & 1 & -1 & 1 & 1 & 4.79 \\
11 & 1 & -1 & 1 & -1 & -1 & -1 & 1 & 1 & 6.56 \\
12 & 1 & 1 & -1 & 1 & 1 & -1 & 1 & -1 & 5.01 \\
13 & 1 & -1 & -1 & -1 & 1 & 1 & 1 & -1 & \\
\hline
\end{tabular}

TABLE 3: Experimental results of the path of steepest ascent.

\begin{tabular}{|c|c|c|c|c|c|}
\hline Variable & $\begin{array}{c}\text { Soluble } \\
\text { starch }(g / L)\end{array}$ & $\begin{array}{l}\text { Yeast extract } \\
(\mathrm{g} / \mathrm{L})\end{array}$ & $\begin{array}{c}\mathrm{K}_{2} \mathrm{HPO}_{4} \\
(\mathrm{~g} / \mathrm{L})\end{array}$ & $\begin{array}{c}\mathrm{MgSO}_{4} \cdot 7 \mathrm{H}_{2} \mathrm{O} \\
(\mathrm{g} / \mathrm{L})\end{array}$ & $\begin{array}{c}\text { Glucoamylase } \\
\text { activity } \\
(\mathrm{U} / \mathrm{mL})\end{array}$ \\
\hline Base point (zero level in the PBD) & 10 & 3 & 1 & 1 & \\
\hline Origin step unit (concentration range of unity level) & 5 & 2 & 0.5 & 0.5 & \\
\hline Slope (estimated coefficient ratio from equation) & 0.6525 & 0.4425 & 0.3775 & 0.2792 & \\
\hline New step unit (slope $\times$ origin step unit) & 3.26 & 0.89 & 0.19 & 0.14 & \\
\hline Run 1 & 13.26 & 3.89 & 1.19 & 1.14 & 5.16 \\
\hline Run 2 & 16.52 & 4.78 & 1.38 & 1.28 & 5.91 \\
\hline Run 3 & 19.78 & 5.67 & 1.57 & 1.42 & 6.88 \\
\hline Run 4 & 23.04 & 6.56 & 1.76 & 1.56 & 8.13 \\
\hline Run 5 & 26.3 & 7.45 & 1.95 & 1.7 & 9.42 \\
\hline Run 6 & 29.56 & 8.34 & 2.14 & 1.84 & 10.48 \\
\hline Run 7 & 32.82 & 9.23 & 2.33 & 1.98 & 11.64 \\
\hline Run 8 & 36.08 & 10.12 & 2.52 & 2.12 & 10.28 \\
\hline Run 9 & 39.34 & 11.01 & 2.71 & 2.26 & 9.67 \\
\hline Run 10 & 42.6 & 11.9 & 2.9 & 2.4 & 9.21 \\
\hline
\end{tabular}

PBD (Table 2) along with the response (glucoamylase activity).The center point experiment was performed to obtain the standard error of the coefficients.

The Plackett-Burman design was based on the first-order model, shown in

$$
G=g_{0}+\sum g_{i} Z_{i}
$$

where $G$ is the glucoamylase activity $(\mathrm{U} / \mathrm{mL}), g_{0}$ is the model intercept, $g_{i}$ is the linear coefficient, and $Z_{i}$ is the level of the independent variable [12].

2.5. Path of Steepest Ascent. Following the first-order model based on PBD, new sets of experiments were performed in the direction of maximum response as described by steepest ascent method [12]. In this approach, the experiments were started at the midlevel of the statistically significant factors that were picked from PBD. The levels of the each factor were increased depending on their magnitude of the main effect. Experiments were continued until no further increase in response was observed (Table 3 ).

2.6. Central Composite Design and Response Surface Methodology. In order to obtain the optimum values of each factor, a CCD was performed. The CCD was used to obtain a quadratic model consisting of factorial points $(-1,+1)$, star points $(-2$, +2 ), and central point ( 0 ) to estimate the variability of the process with glucoamylase yield as the response (Table 4).

Response surface methodology was employed to optimize the four selected significant factors, namely, soluble starch $\left(Z_{1}\right)$, yeast extract $\left(Z_{2}\right), \mathrm{K}_{2} \mathrm{HPO}_{4}\left(Z_{3}\right)$, and $\mathrm{MgSO}_{4} \cdot 7 \mathrm{H}_{2} \mathrm{O}\left(Z_{4}\right)$, which increase the glucoamylase production. In this methodology, a 4-factor, 5-level CCD with 31 runs was employed (Table 5). 
TABLE 4: Ranges of the independent variables used in central composite design.

\begin{tabular}{lccccccc}
\hline \multirow{2}{*}{ Symbol } & \multirow{2}{*}{ Variable } & Unit & -2 & -1 & \multicolumn{3}{c}{ Coded level } \\
& & & $(\mathrm{g} / \mathrm{L})$ & 26.3 & 29.56 & 32.82 & 36.08 \\
\hline$Z_{1}$ & Soluble starch & $(\mathrm{g} / \mathrm{L})$ & 7.45 & 8.34 & 9.23 & 39.34 \\
$Z_{2}$ & Yeast extract & $(\mathrm{g} / \mathrm{L})$ & 1.95 & 2.14 & 2.33 & 10.12 \\
$Z_{3}$ & $\mathrm{~K}_{2} \mathrm{HPO}_{4}$ & $(\mathrm{~g} / \mathrm{L})$ & 1.7 & 1.84 & 1.98 & 2.52 & 2.12 \\
$Z_{4}$ & $\mathrm{MgSO}_{4} \cdot 7 \mathrm{H}_{2} \mathrm{O}$ & & & & & 2.71 \\
\hline
\end{tabular}

TABLE 5: Central composite design matrix for the experimental design and predicted responses for glucoamylase activity.

\begin{tabular}{|c|c|c|c|c|c|c|}
\hline \multirow{2}{*}{ Trial } & \multicolumn{4}{|c|}{ Coded variable level } & \multicolumn{2}{|c|}{ Glucoamylase activity (U/mL) } \\
\hline & $Z_{1}$ & $Z_{2}$ & $Z_{3}$ & $Z_{4}$ & Observed & Predicted \\
\hline 1 & -1 & -1 & 1 & -1 & 10.73 & 10.498 \\
\hline 2 & 0 & 0 & 0 & 0 & 11.56 & 11.65 \\
\hline 3 & 1 & 1 & 1 & 1 & 10.2 & 10.156 \\
\hline 4 & 0 & 0 & 0 & 0 & 11.72 & 11.65 \\
\hline 5 & 0 & 0 & 2 & 0 & 9.42 & 9.845 \\
\hline 6 & 0 & 0 & 0 & 2 & 8.41 & 9.031 \\
\hline 7 & 1 & 1 & -1 & -1 & 8.38 & 8.186 \\
\hline 8 & -1 & -1 & -1 & -1 & 10.56 & 10.362 \\
\hline 9 & -1 & -1 & 1 & 1 & 8.93 & 8.883 \\
\hline 10 & -1 & 1 & 1 & -1 & 11.87 & 11.737 \\
\hline 11 & -1 & 1 & -1 & 1 & 10.22 & 9.779 \\
\hline 12 & 1 & 1 & 1 & -1 & 10.4 & 10.191 \\
\hline 13 & -2 & 0 & 0 & 0 & 11.35 & 11.703 \\
\hline 14 & 0 & 0 & 0 & 0 & 11.82 & 11.65 \\
\hline 15 & 1 & -1 & -1 & 1 & 9.42 & 9.311 \\
\hline 16 & 1 & -1 & -1 & -1 & 8.96 & 8.996 \\
\hline 17 & 2 & 0 & 0 & 0 & 9.54 & 9.758 \\
\hline 18 & 0 & 0 & 0 & 0 & 11.62 & 11.65 \\
\hline 19 & 0 & 0 & 0 & -2 & 9.77 & 9.72 \\
\hline 20 & 0 & 0 & 0 & 0 & 11.48 & 11.65 \\
\hline 21 & 1 & -1 & 1 & -1 & 9.02 & 9.219 \\
\hline 22 & -1 & 1 & -1 & -1 & 9.56 & 9.82 \\
\hline 23 & 0 & 0 & -2 & 0 & 8.52 & 8.666 \\
\hline 24 & 0 & -2 & 0 & 0 & 8.69 & 8.935 \\
\hline 25 & 0 & 0 & 0 & 0 & 11.71 & 11.65 \\
\hline 26 & -1 & 1 & 1 & 1 & 11.1 & 10.735 \\
\hline 27 & 0 & 0 & 0 & 0 & 11.64 & 11.65 \\
\hline 28 & 1 & 1 & -1 & 1 & 9.21 & 9.113 \\
\hline 29 & 1 & -1 & 1 & 1 & 9.16 & 8.571 \\
\hline 30 & 0 & 2 & 0 & 0 & 9.65 & 9.976 \\
\hline 31 & -1 & -1 & -1 & 1 & 9.83 & 9.71 \\
\hline
\end{tabular}

A quadratic equation was used to fit the response to the independent variables as given in (2)

$$
G=g_{0}+\sum g_{i} Z_{i}+\sum g_{i i} Z_{i}^{2}+\sum g Z_{i} Z_{j}
$$

where $G$ is the predicted response of the glucoamylase activity $(\mathrm{U} / \mathrm{mL}), g_{0}$ is the offset term (constant), $g_{i}$ is the linear effect, $g_{i j}$ is the quadratic effect when $i=j$ and interaction effect when $i<j, g_{i i}$ is the squared term, and $Z_{i}$ and $Z_{j}$ are the coded independent variables for statistical calculations according to

$$
Z=\frac{R-R_{0}}{\Delta R}
$$

where $Z$ is the coded value of the independent variable, $R$ is the real value of the independent variable, $R_{0}$ is the real value of the independent variable on the center point, and $\Delta R$ is the step change value [12]. 
TABLE 6: Statistical analysis of PBD on glucoamylase activity.

\begin{tabular}{lcccccc}
\hline Variables & Main effect & Coefficients & Standard error & $t$ value & $P$ value & Confidence level (\%) \\
\hline Intercept & & 4.8542 & 0.065 & 74.68 & $<0.0001$ & \\
$A$ & 1.3050 & 0.6525 & 0.065 & 10.04 & 0.002 & $99.80^{*}$ \\
$B$ & 0.8850 & 0.4425 & 0.065 & 6.81 & 0.006 & 9.237 \\
$C$ & -0.1917 & -0.0958 & 0.065 & -1.47 & $0.230^{*}$ & 76.30 \\
$D$ & 0.7550 & 0.3775 & 0.065 & 5.81 & 0.010 & $9.00^{*}$ \\
$E$ & 0.1217 & 0.0608 & 0.065 & 0.94 & 0.418 & 58.20 \\
$F$ & -0.0250 & -0.0125 & 0.065 & -0.19 & 0.860 & 14.00 \\
$G$ & 0.5583 & 0.2792 & 0.065 & 4.29 & 0.023 & $97.70^{*}$ \\
$H$ & 0.3150 & 0.1575 & 0.065 & 2.42 & 0.094 & 90.60 \\
\hline
\end{tabular}

${ }^{*}$ Statistically significant at $95 \%$ confidence level.

2.7. Statistical Analysis. Statistical analysis of the model developed by PBD and CCD was evaluated by analysis of variance (ANOVA) concept, using the statistical software package MINITAB-14 (MINITAB Inc., PA, USA). The polynomial model was statistically verified by using various parameters like linear regression coefficient $R^{2}, F$ value, $t$ value, absolute average relative deviation (AARD), and predicted residual sum of squares (PRESS).

\section{Results and Discussion}

3.1. Optimization by Plackett-Burman Design. The significance of the eight media components, namely, soluble starch (A), yeast extract (B), $\mathrm{KH}_{2} \mathrm{PO}_{4}(\mathrm{C}), \mathrm{K}_{2} \mathrm{HPO}_{4}$ (D), $\mathrm{NaCl}(\mathrm{E}), \mathrm{CaCl}_{2}$ (F), $\mathrm{MgSO}_{4} \cdot 7 \mathrm{H}_{2} \mathrm{O}(\mathrm{G})$ and Vogel's trace elements solution $(\mathrm{H})$ for the production of glucoamylase was investigated as given by $\mathrm{PBD}$. The response of $\mathrm{PBD}$ portrayed wide variation of activity from 3.02 to $6.56 \mathrm{U} / \mathrm{mL}$ (Table 6), which depicts the importance of attaining higher glucoamylase production.

Table 6 shows the main effects, coefficients, and standard error along with the $t, P$ values and confidence levels of these components on the response (glucoamylase production). The positive and negative values of the coefficients represent the increase and decrease in glucoamylase production against the respective concentration of the components. The main effects characterize the deviations of the average between high and low levels for each one of the factors. If the main effect of a factor is positive, the glucoamylase production increases as the factor is changed from low to high level whereas the opposite behaviour (a decrease in the glucoamylase production) is observed for a negative main effect. In the current study, the media components A, B, D, E, G, and $\mathrm{H}$ increased the glucoamylase production at higher level whereas a decrease in response was observed for $\mathrm{C}$ and $\mathrm{F}$ components.

Based on the ANOVA results, the effects of only A (99.8\%), B (99.4\%), D (99\%), and G (97.7\%) had confidence levels greater than 95\% and, hence, identified as the most significant parameters influencing glucoamylase production (Table 6).

The same phenomena were explained graphically using Pareto chart (Figure 1). It explains the importance of

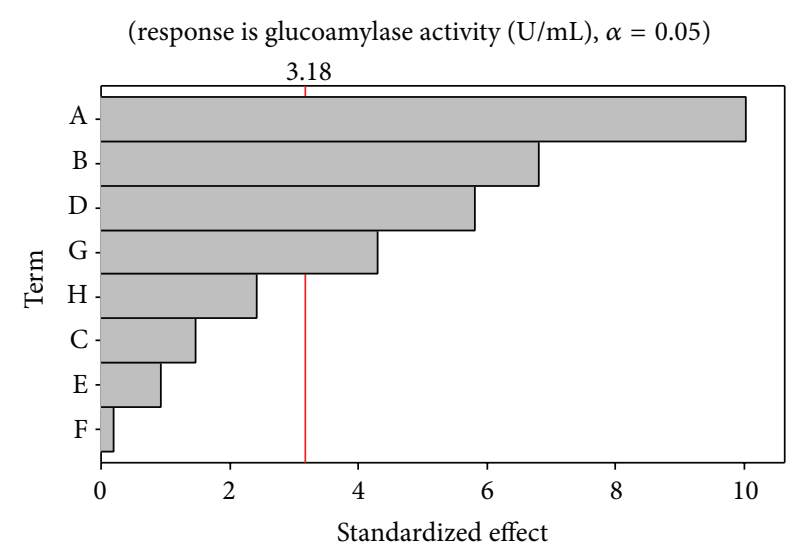

Figure 1: Pareto plot shows the effect of media on glucoamylase activity.

the individual main effect of each factor to determine whether they are significantly different from zero. These values are represented by horizontal columns in the Pareto chart. For a 95\% confidence level and three degrees of freedom, the $t$ value equals 3.18 and is shown in the plot as a vertical line. This indicates the minimum statistically significant effect for 95\% confidence level. It is clear from the Pareto chart that the four factors A, B, D, and G are significant, and therefore these four factors were taken up for further studies.

The production of glucoamylase by Humicola grisea depends on various types of nutrients provided. It majorly depends on type of carbon and nitrogen source used. In the present study, starch plays a significant role (positive effect) as a carbon source. Literature abounds in instances which show the prominent role played by starch as a carbon source for high glucoamylase production $[5,9,10]$. Starch (A) seems to have an "inductive effect" and portrays a significant role in glucoamylase production [11].

Similar to starch as a significant carbon source, the current study indicated the importance of yeast extract (B), as a nitrogen source, in aiding the production of glucoamylase. As in many other studies, yeast extract helps in the development of mycelial structures with a corresponding higher yield of enzymes [18]. Similar kind of results was obtained for glucoamylase production that proved the positive effect played by yeast extract $[5,6,9]$. 
$\mathrm{K}_{2} \mathrm{HPO}_{4}$ (D) was also found to have a positive effect on glucoamylase production due to the possible buffering effect on the culture medium. The fact that $\mathrm{K}_{2} \mathrm{HPO}_{4}$ has a positive role in the enzyme production is well in concordance with the results obtained by other researchers $[5,6,19]$. Similarly, a positive effect was observed with the addition of $\mathrm{MgSO}_{4}$ (G). The experimental observations are in agreement with the studies performed by Kumar and Satyanarayana [5] and Nguyen et al. [6].

Based on the regression analysis, the first-order model for the PBD with coded values is given by

$$
\begin{aligned}
G= & 4.8542+0.0625 A+0.4425 B-0.0958 C \\
& +0.3775 D+0.0608 E-0.0125 F \\
& +0.2792 G+0.1575 H .
\end{aligned}
$$

The $R^{2}$ value for the above model was found to be 0.9859 that implies that $98.59 \%$ of the variability of the data can be explained by the model.

From Table 2 it is clear that the glucoamylase production at the center point $(4.57 \mathrm{U} / \mathrm{mL})$ is almost close to the average glucoamylase production value $(4.85 \mathrm{U} / \mathrm{mL})$ at the factorial points which suggest that there is an absence of curvature $[20,21]$. Therefore, steepest ascent method was performed to obtain the levels of the factors which were close to the optimum [22].

3.2. The Path Steepest Ascent. In the path of steepest ascent methodology, experiments were conducted using the four significant factors obtained from the first-order model given by PBD. This was done in order to determine the vicinity of optimum by changing the levels of the said factors with respect to the magnitude of the coefficients. By taking the center point of the four significant factors obtained from PBD (the other four factors were maintained at the low level of PBD), the path of steepest ascent was started and moved along the path in which the concentration of all the four factors increased (since all the four factors had positive effects).

The experimental design and the results of the path of steepest ascent are shown in Table 3. From the table, it is inferred that the highest response of glucoamylase activity of $11.64 \mathrm{U} / \mathrm{mL}$ was observed in Run 7 , when medium composition was soluble starch $32.82 \mathrm{~g} / \mathrm{L}$, yeast extract $9.23 \mathrm{~g} / \mathrm{L}$, $\mathrm{K}_{2} \mathrm{HPO}_{4} 2.33 \mathrm{~g} / \mathrm{L}$, and $\mathrm{MgSO}_{4} \cdot 7 \mathrm{H}_{2} \mathrm{O} 1.98 \mathrm{~g} / \mathrm{L}$. Moreover, further increments in concentration of the media components resulted in a dip of glucoamylase production, which may be due to the inhibitory effect of high concentration of one of the components. Thus, it was obvious that the production of glucoamylase stabilized in the seventh run which proved that the media compositions were in the vicinity of optimum. Hence, this composition was chosen for further studies.

3.3. Central Composite Design and Response Surface Methodology. The CCD was conducted in order to determine the true optimum concentrations of the four factors (soluble starch, yeast extract, $\mathrm{K}_{2} \mathrm{HPO}_{4}$, and $\mathrm{MgSO}_{4} \cdot 7 \mathrm{H}_{2} \mathrm{O}$ ) for glucoamylase production. The levels of the factors were chosen from the results of the path of steepest ascent (Run number 7 ), and the design matrix is shown in Table 5. A total of 31 experiments were performed according to the design matrix, and the experimental results are shown in Table 5 along with the predicted glucoamylase activity. The experimental results were fitted with a second-order polynomial equation as a function of the four factors with coded values and are given as follows:

$$
\begin{aligned}
G= & 11.65-0.4863 Z_{1}+0.2604 Z_{2}+0.2946 Z_{3} \\
& -0.1721 Z_{4}-0.2299 Z_{1}^{2}-0.5486 Z_{2}^{2} \\
& -0.5986 Z_{3}^{2}-0.5686 Z_{4}^{2}-0.0669 Z_{1} Z_{2} \\
& +0.0219 Z_{1} Z_{3}+0.2419 Z_{1} Z_{4}+0.4456 Z_{2} Z_{3} \\
& +0.1531 Z_{2} Z_{4}-0.2406 Z_{3} Z_{4},
\end{aligned}
$$

where $G$ is the glucoamylase activity $(\mathrm{U} / \mathrm{mL})$ and $Z_{1}, Z_{2}$, $Z_{3}$, and $Z_{4}$ are soluble starch, yeast extract, $\mathrm{K}_{2} \mathrm{HPO}_{4}$, and $\mathrm{MgSO}_{4} \cdot 7 \mathrm{H}_{2} \mathrm{O}$, respectively.

The ANOVA results (Table 7) obtained in the present study are in good agreement with the general facts of higher $F$, predicted $R^{2}$ values, and lower PRESS values which specify a better fit [12]. Similarly, $P$ values $<0.05$ indicate that the model terms were significant. In this study, all the linear, square effects of $Z_{1}, Z_{2}, Z_{3}$, and $Z_{4}$ and interactive effects of $Z_{1} Z_{4}, Z_{2} Z_{3}$, and $Z_{3} Z_{4}$ were significant for glucoamylase production. Therefore by removing the insignificant terms $\left(Z_{1} Z_{2}, Z_{1} Z_{3}\right.$, and $\left.Z_{2} Z_{4}\right)$ a reduced model was obtained as follows:

$$
\begin{aligned}
G= & 11.65-0.4863 Z_{1}+0.2604 Z_{2}+0.2946 Z_{3} \\
& -0.1721 Z_{4}-0.2299 Z_{1}^{2}-0.5486 Z_{2}^{2} \\
& -0.5986 Z_{3}^{2}-0.5686 Z_{4}^{2}+0.2419 Z_{1} Z_{4} \\
& +0.4456 Z_{2} Z_{3}-0.2406 Z_{3} Z_{4} .
\end{aligned}
$$

For this reduced model, the values of various statistical parameters were as follows: $F$ value: 26.89 , coefficient of determination $\left(R^{2}\right): 0.9397$, predicted $R^{2}: 0.7688$, adjusted $R^{2}$ : 0.9047, and PRESS: 9.47. The increase in $F$ value, increase in predicted $R^{2}$ value, and a decrease in the PRESS value indicate that the reduced model fits the data in a better way. This is corroborated by the higher $F$ values of the model than the $F$ value of lack of fit $[23,24]$. The linear trend line in Figure 2 shows that the data are normally distributed which confirms that the model fits well with the experimental results. Therefore, the major assumptions of the model (normal distribution of errors, same errors of variance, randomization, and zero mean error) stand validated.

In addition to these, another statistical parameter, AARD (\%) (7), was calculated. It explains the extent to which the predicted values differ from the experimental values and a lesser value $(<5 \%)$ is preferred for a good model [25]. Consider

$$
\operatorname{AARD}=\frac{I}{N} \sum_{i=1}^{N}\left[\frac{G_{i}^{\mathrm{obs}}-G_{i}^{\mathrm{pre}}}{G_{i}^{\mathrm{obs}}}\right] \times 100,
$$

where $N$ is the number of experimental data points. 
TABLE 7: Analysis of variance (ANOVA) for the fitted second-order polynomial model for optimization of glucoamylase production.

\begin{tabular}{|c|c|c|c|c|c|}
\hline Variables & Coefficient estimate & Sum of squares & Degrees of freedom & $F$ value & $P$ value \\
\hline Model & 11.65 & 38.9579 & 14 & 22.06 & $<0.0001$ \\
\hline$Z_{1}$ & -0.48625 & 10.0955 & 1 & 44.98 & $<0.0001$ \\
\hline$Z_{2}$ & 0.260417 & 5.6745 & 1 & 12.9 & 0.002 \\
\hline$Z_{3}$ & 0.294583 & 1.6276 & 1 & 16.51 & 0.001 \\
\hline$Z_{4}$ & -0.172083 & 2.0827 & 1 & 5.63 & 0.03 \\
\hline$Z_{1} Z_{1}$ & -0.229896 & 0.1854 & 1 & 11.98 & 0.003 \\
\hline$Z_{2} Z_{2}$ & -0.548646 & 5.5598 & 1 & 68.23 & $<0.0001$ \\
\hline$Z_{3} Z_{3}$ & -0.598646 & 8.3763 & 1 & 81.23 & $<0.0001$ \\
\hline$Z_{4} Z_{4}$ & -0.568646 & 9.2467 & 1 & 73.3 & $<0.0001$ \\
\hline$Z_{1} Z_{2}$ & -0.066875 & 0.0716 & 1 & 0.57 & 0.462 \\
\hline$Z_{1} Z_{3}$ & 0.021875 & 0.0077 & 1 & 0.06 & 0.809 \\
\hline$Z_{1} Z_{4}$ & 0.241875 & 0.9361 & 1 & 7.42 & 0.015 \\
\hline$Z_{2} Z_{3}$ & 0.445625 & 3.1773 & 1 & 25.19 & $<0.0001$ \\
\hline$Z_{2} Z_{4}$ & 0.153125 & 0.3752 & 1 & 2.97 & 0.104 \\
\hline$Z_{3} Z_{4}$ & -0.240625 & 0.9264 & 1 & 7.34 & 0.015 \\
\hline Residual & & 2.0185 & 16 & & \\
\hline Lack of fit & & 1.9431 & 10 & 15.46 & 0.002 \\
\hline Pure error & & 0.0754 & 6 & & \\
\hline Total & & 40.9763 & 30 & & \\
\hline
\end{tabular}

$R^{2}=95.07 \%, R_{\text {Adj }}^{2}=90.76 \%, R_{\text {Pre }}^{2}=72.44 \%$, and PRESS: 11.29 .

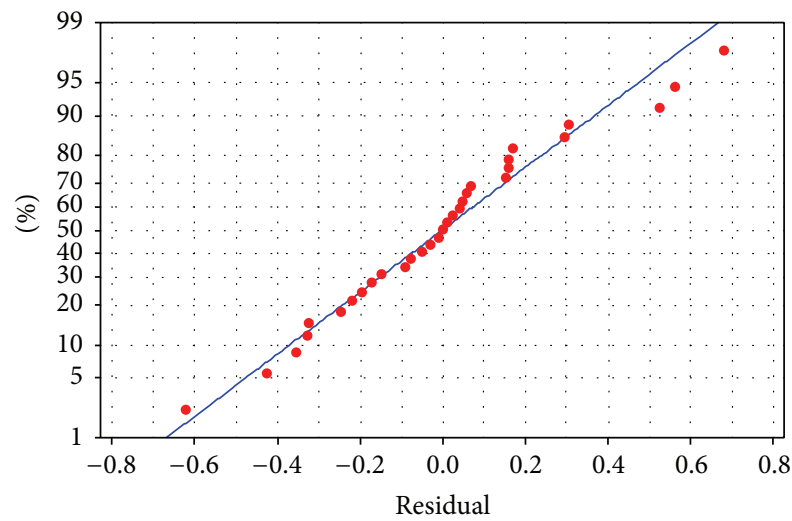

FIGURE 2: Normal probability plot of glucoamylase production.

For the current system, an AARD of 2.07\% was obtained which implies that the model is adequate for the data.

In order to visualize the interaction effects between each variable on glucoamylase production, two-dimensional contour plots are shown graphically in Figure 3 . The interaction effects between two factors are shown with other two variables kept constant at their center value. It is clear from the plots that there is a change in glucoamylase production with respect to the low or high levels of the factors. The shape of the plot determines the extent of interaction between the factors. The elliptical shape of the contour plot between the factors, soluble starch and $\mathrm{MgSO}_{4} \cdot 7 \mathrm{H}_{2} \mathrm{O}$ and yeast extract and $\mathrm{K}_{2} \mathrm{HPO}_{4}$, indicates the significant interaction effect and an increase in glucoamylase production at their higher values. The interaction effect between $\mathrm{K}_{2} \mathrm{HPO}_{4}$ and $\mathrm{MgSO}_{4} \cdot 7 \mathrm{H}_{2} \mathrm{O}$ indicates an elliptical shape with negative effect (decrease in glucoamylase production at higher values). The circular shape of the contour plots among the remaining variables confirms that there was no or less interaction between them.

The same phenomena are numerically shown in Table 7 $(P<0.05$ : presence of interaction and $P>0.05$ : no interaction). The reduced regression model was solved for maximum glucoamylase production using the response optimizer tool in MINITAB 14.0 and the optimum levels of each variable in uncoded units were as follows: soluble starch $=$ $28.41 \mathrm{~g} / \mathrm{L}$, yeast extract $=9.61 \mathrm{~g} / \mathrm{L}, \mathrm{K}_{2} \mathrm{HPO}_{4}=2.42 \mathrm{~g} / \mathrm{L}$, and $\mathrm{MgSO}_{4} \cdot 7 \mathrm{H}_{2} \mathrm{O}=1.91 \mathrm{~g} / \mathrm{L}$, all of which were located within the experimental range. The predicted glucoamylase activity under these optimum conditions was $12.15 \mathrm{U} / \mathrm{mL}$.

3.4. Experimental Verification of the Model. In order to validate these results, experiments were done in triplicate at the optimized values. Under the optimized conditions, the predicted response for glucoamylase activity was $12.15 \mathrm{U} / \mathrm{mL}$ and the average of observed experimental values was $12.27 \pm$ $0.16 \mathrm{U} / \mathrm{mL}$. The good correlation between the observed and predicted values confirms the adequacy of the model. This optimization strategy led to the enhancement of glucoamylase production from $4.57 \mathrm{U} / \mathrm{mL}$ (unoptimized medium) to $12.27 \mathrm{U} / \mathrm{mL}$ (optimized medium), a 2.68 -fold increase. In addition to this, the optimized glucoamylase activity was found to be higher than the available literature value for various thermophilic fungi such as Scytalidium thermophilum $15.8(3.62 \mathrm{U} / \mathrm{mL})$ [26], Thermomyces lanuginosus A.13.37 (2.8 U/mL) [2], and Thermomyces lanuginosus ATCC $200065(7.4 \mathrm{U} / \mathrm{mL})$ [27] and comparable with Thermomyces lanuginosus TO3 (13 U/mL) [28]. 


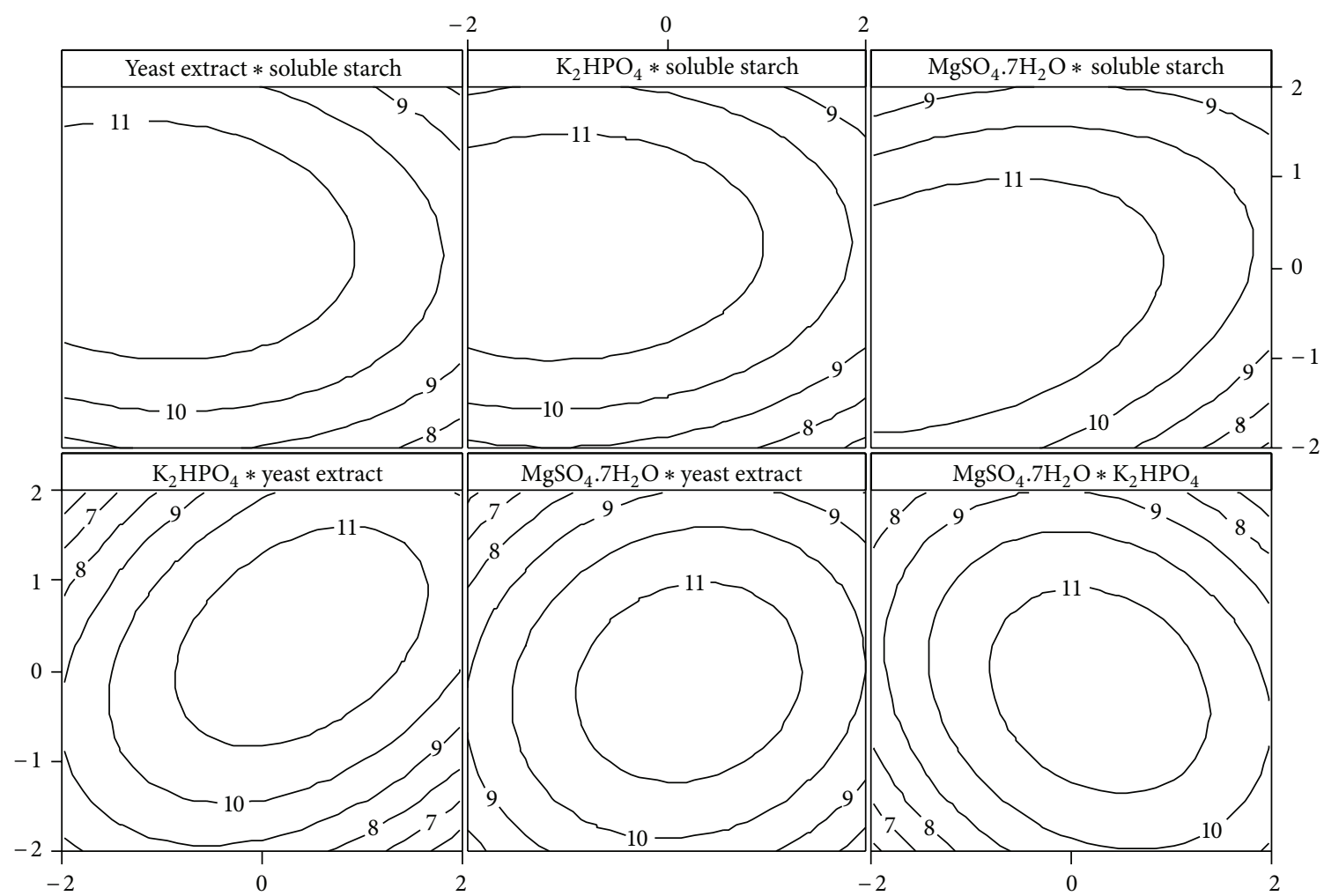

FIGURE 3: Contour plots of interaction effect of variables on glucoamylase activity $(\mathrm{U} / \mathrm{mL})$.

\section{Conclusion}

In the present study, we have demonstrated the use of statistical design for the rapid identification and optimization of significant media components for the production of glucoamylase by thermophilic fungus Humicola grisea MTCC 352 which resulted in 2.68-fold enhancement of glucoamylase activity as compared to the unoptimized medium. Initially, eight media components were screened using PBD for their effect on the production of glucoamylase. Out of them, soluble starch, yeast extract, $\mathrm{K}_{2} \mathrm{HPO}_{4}$, and $\mathrm{MgSO}_{4} \cdot 7 \mathrm{H}_{2} \mathrm{O}$ were found to be statistically significant. The method of steepest ascent identified the region of optimum. The values of the four parameters were optimized by employing CCD (soluble starch: $28.41 \mathrm{~g} / \mathrm{L}$, yeast extract: $9.61 \mathrm{~g} / \mathrm{L}, \mathrm{K}_{2} \mathrm{HPO}_{4}$ : $2.42 \mathrm{~g} / \mathrm{L}$, and $\mathrm{MgSO}_{4} \cdot 7 \mathrm{H}_{2} \mathrm{O}: 1.91 \mathrm{~g} / \mathrm{L}$ ). The proposed secondorder model was validated as the difference between the obtained experimental activity of $12.27 \mathrm{U} / \mathrm{mL}$ and the predicted activity of 12.15 was meagre. Thus, the optimized media composition found out in the present investigation might reduce the overall cost of the medium and provides a basis for further studies on the large scale glucoamylase production.

\section{Conflict of Interests}

The authors declare that there is no conflict of interests regarding the publication of this paper.

\section{Acknowledgment}

The authors gratefully acknowledge the Department of Biotechnology, MIT, Manipal University, for providing the facilities to carry out the research work.

\section{References}

[1] D. Norouzian, A. Akbarzadeh, J. M. Scharer, and M. Moo Young, "Fungal glucoamylases," Biotechnology Advances, vol. 24 , no. 1, pp. 80-85, 2006.

[2] E. Gomes, S. R. De Souza, R. P. Grandi, and R. D. Silva, "Production of thermostable glucoamylase by newly isolated Aspergillus flavus a 1.1 and Thermomyces lanuginosus a 13.37," Brazilian Journal of Microbiology, vol. 36, no. 1, pp. 75-82, 2005.

[3] T. E. Abraham, J. R. Joseph, L. B. V. Bindhu, and K. K. Jayakumar, "Crosslinked enzyme crystals of glucoamylase as a potent catalyst for biotransformations," Carbohydrate Research, vol. 339, no. 6, pp. 1099-1104, 2004.

[4] L. Campos and C. R. Felix, "Purification and characterization of a glucoamylase from Humicola grisea," Applied and Environmental Microbiology, vol. 61, no. 6, pp. 2436-2438, 1995.

[5] P. Kumar and T. Satyanarayana, "Optimization of culture variables for improving glucoamylase production by alginateentrapped Thermomucor indicae-seudaticae using statistical methods," Bioresource Technology, vol. 98, no. 6, pp. 1252-1259, 2007.

[6] Q. D. Nguyen, J. M. Rezessy-Szabó, and Á. Hoschke, “Optimization of composition of media for the production of amylolytic 
enzymes by Thermomyces lanuginosus ATCC 34626," Food Technology and Biotechnology, vol. 38, no. 3, pp. 229-234, 2000.

[7] L. R. O. Tosi, H. F. Terenzi, and J. A. Jorge, "Purification and characterization of an extracellular glucoamylase from the thermophilic fungus Humicola grisea var. thermoidea," Canadian Journal of Microbiology, vol. 39, no. 9, pp. 846-852, 1993.

[8] S. K. Singh, B. Vijay, V. Mediratta, O. P. Ahlawat, and S. Kamal, "Molecular characterization of Humicola grisea isolates associated with Agaricus bisporus compost," Current Science, vol. 89, no. 10, pp. 1745-1749, 2005.

[9] L. Mohamed, M. Zakaria, A. Ali et al., "Optimization of growth and extracellular glucoamylase production by Candida famata isolate," African Journal of Biotechnology, vol. 6, no. 22, pp. 2590-2595, 2007.

[10] J. Arnthong, B. Wanitchaploy, K. Sakai, J. Sanglie, and V. Kitpreechavanich, "Statistical screening of factors affecting glucoamylase production by a thermotolerant Rhizopus microsporus tistr 3518 using plackett-burman design," African Journal of Biotechnology, vol. 9, no. 43, pp. 7312-7316, 2010.

[11] V. S. Prajapati, U. B. Trivedi, and K. C. Patel, "Optimization of glucoamylase production by Colletotrichum sp. KCP1 using statistical methodology," Food Science and Biotechnology, vol. 22, no. 1, pp. 31-38, 2013.

[12] D. C. Montgomery, Design and Analysis of Experiments, John Wiley \& Sons, Hoboken, NJ, USA, 2005.

[13] Y. He and T. Tan, "Use of response surface methodology to optimize culture medium for production of lipase with Candida sp. 99-125," Journal of Molecular Catalysis B: Enzymatic, vol. 43, no. 1-4, pp. 9-14, 2006.

[14] Y. Wee, L. V. A. Reddy, K. Chung, and H. Ryu, "Optimization of chitosanase production from Bacillus sp. RKY3 using statistical experimental designs," Journal of Chemical Technology and Biotechnology, vol. 84, no. 9, pp. 1356-1363, 2009.

[15] S. Liu, Y. Fang, M. Lv, S. Wang, and L. Chen, “Optimization of the production of organic solvent-stable protease by Bacillus sphaericus DS11 with response surface methodology," Bioresource Technology, vol. 101, no. 20, pp. 7924-7929, 2010.

[16] H. J. Vogel, "A convenient growth medium for Neurospora (Medium N)," Microbial Genetics Bulletin, vol. 13, pp. 42-43, 1956.

[17] Q. D. Nguyen, J. M. Rezessy-Szabó, M. Claeyssens, I. Stals, and Á. Hoschke, "Purification and characterisation of amylolytic enzymes from thermophilic fungus Thermomyces lanuginosus strain ATCC 34626," Enzyme and Microbial Technology, vol. 31, no. 3, pp. 345-352, 2002.

[18] M. Suutari, U. Lignell, A. Hyvärinen, and A. Nevalainen, "Media for cultivation of indoor streptomycetes," Journal of Microbiological Methods, vol. 51, no. 3, pp. 411-416, 2002.

[19] S. Kumar and T. Satyanarayana, "Medium optimization for glucoamylase production by a yeast, Pichia subpelliculosa ABWF64, in submerged cultivation," World Journal of Microbiology and Biotechnology, vol. 17, no. 1, pp. 83-87, 2001.

[20] S. Raja, V. R. Murty, V. Thivaharan, V. Rajasekar, and V. Ramesh, "Aqueous two phase systems for the recovery of biomoleculesa review," Science and Technology, vol. 1, pp. 7-16, 2011.

[21] S. Raja and V. R. Murty, "Optimization of aqueous two-phase systems for the recovery of soluble proteins from tannery wastewater using response surface methodology," Journal of Engineering, vol. 2013, Article ID 217483, 10 pages, 2013.
[22] X. Gao, S. Y. Qiao, and W. Q. Lu, "Determination of an economical medium for growth of Lactobacillus fermentum using response surface methodology," Letters in Applied Microbiology, vol. 49, no. 5, pp. 556-561, 2009.

[23] M. Dilipkumar, M. Rajasimman, and N. Rajamohan, "Optimization of inulinase production from garlic by Streptomyces sp. in solid state fermentation using statistical designs," Biotechnology Research International, vol. 2011, Article ID 708043, 7 pages, 2011.

[24] N. Sindhu, S. Kalaivani, and I. Regupathi, "Bovine serum albumin partitioning in aqueous two-phase systems: effects of variables and optimization," Bioprocessing Journal, vol. 12, no. 1, pp. 29-41, 2013.

[25] S. Raja and V. R. Murty, "Development and evaluation of environmentally benign aqueous two phase systems for the recovery of proteins from tannery waste water," ISRN Chemical Engineering, vol. 2012, Article ID 290471, 9 pages, 2012.

[26] M. Cereia, L. H. S. Guimarães, S. C. Peixoto-Nogueira et al., "Glucoamylase isoform (GAII) purified from a thermophilic fungus Scytalidium thermophilum 15.8 with biotechnological potential," African Journal of Biotechnology, vol. 5, no. 12, pp. 1239-1245, 2006.

[27] T. S. Thorsen, A. H. Johnsen, K. Josefsen, and B. Jensen, "Identification and characterization of glucoamylase from the fungus Thermomyces lanuginosus," Biochimica et Biophysica Acta-Proteins and Proteomics, vol. 1764, no. 4, pp. 671-676, 2006.

[28] A. Z. L. Gonçalves, A. F. A. Carvalho, R. Da Silva, and E. Gomes, "Localization and partial characterization of thermostable glucoamylase produced by newly isolated Thermomyces lanuginosus TO3 in submerged fermentation," Brazilian Archives of Biology and Technology, vol. 51, no. 4, pp. 857-865, 2008. 

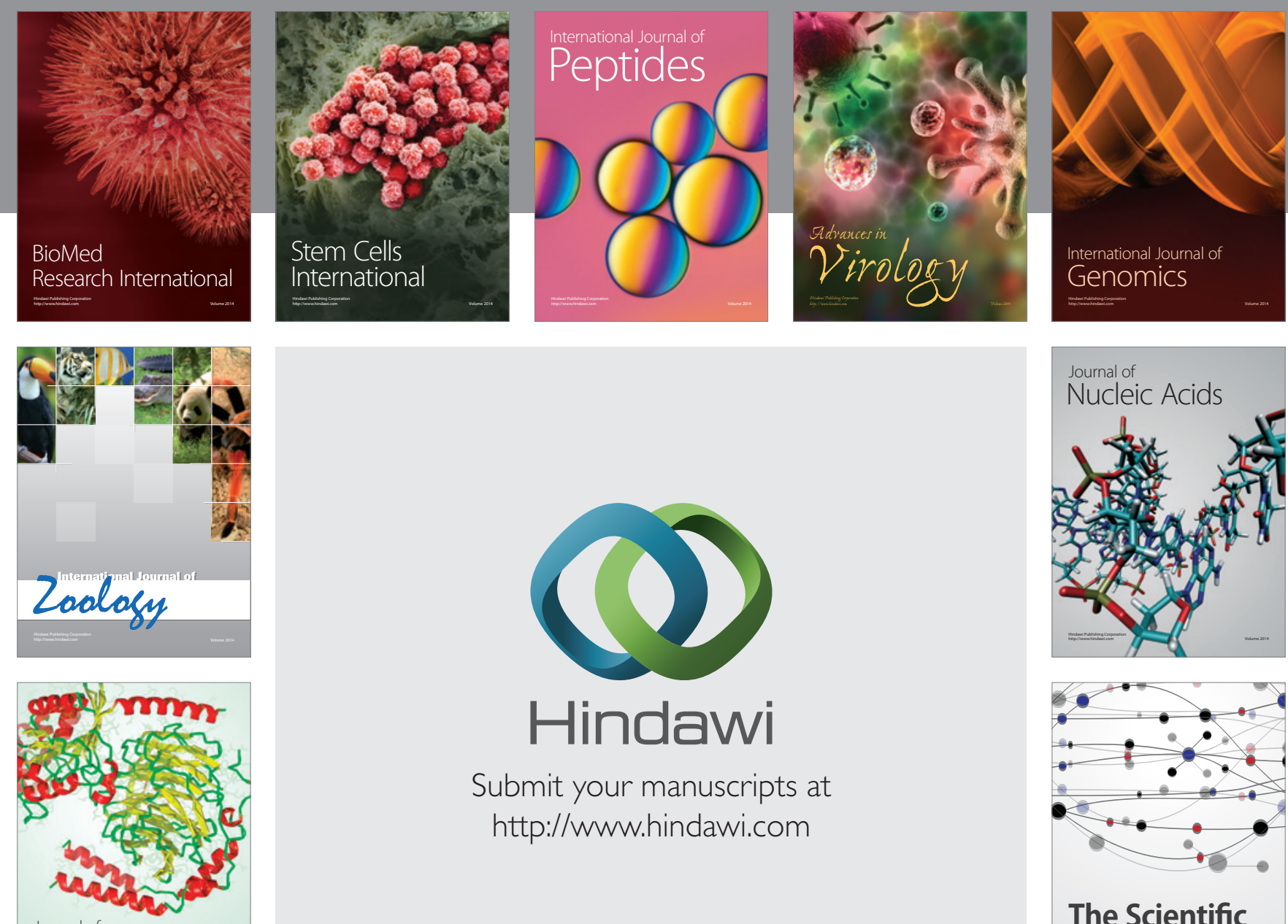

Submit your manuscripts at

http://www.hindawi.com

Journal of
Signal Transduction
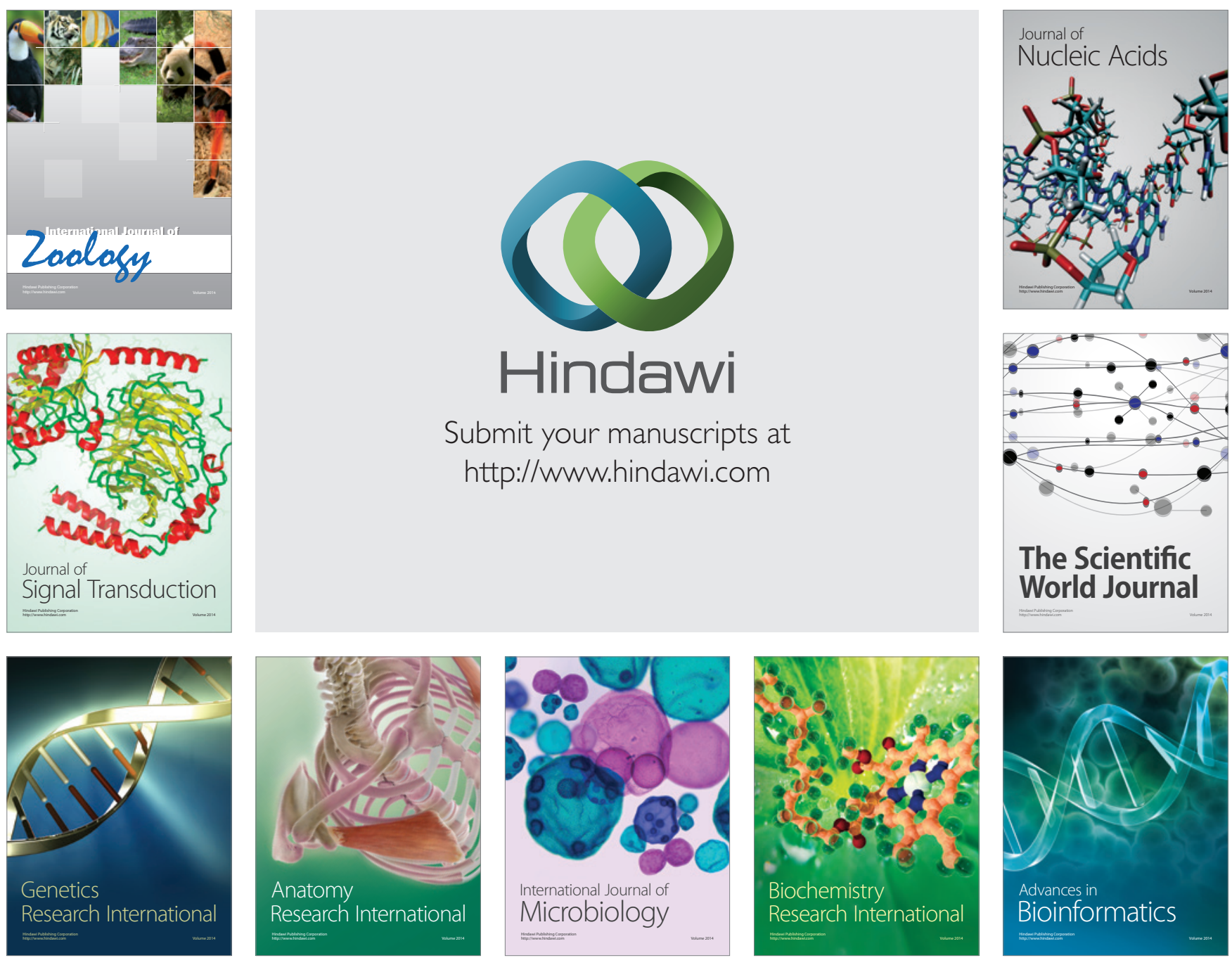

The Scientific World Journal
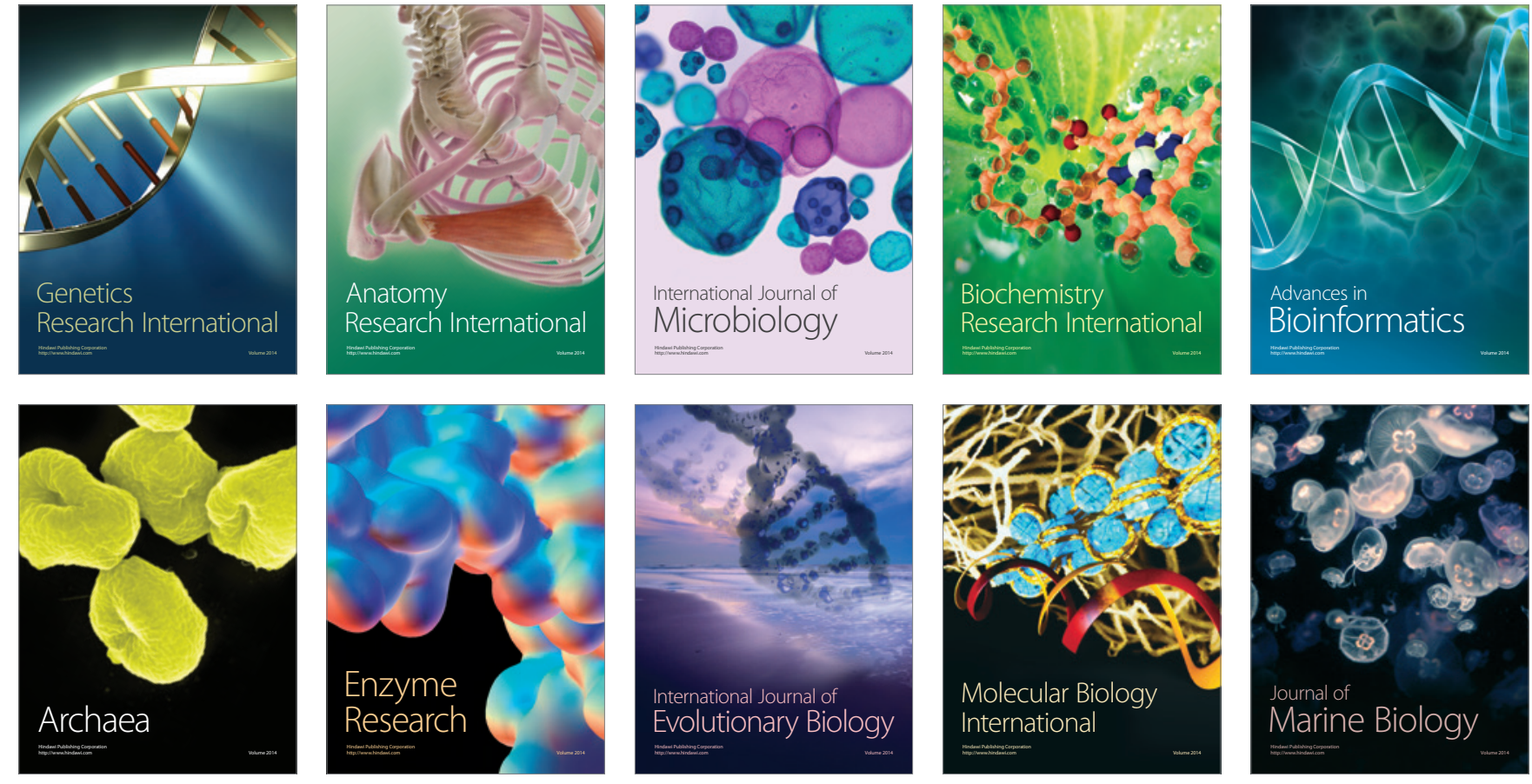